\title{
Toward the Development of a Gene Index to the Human Genome: An Assessment of the Nature of High-throughput EST Sequence Data
}

\author{
Jeffrey S. Aaronson, ${ }^{1}$ Barbara Eckman, Richard A. Blevins, \\ Joseph A. Borkowski, Joseph Myerson, Shahid Imran, and \\ Keith O. Elliston ${ }^{2}$
}

\begin{abstract}
Merck Research Laboratories, Department of Bioinformatics, Rahway, New Jersey 07065, and West Point, Pennsylvania 19486
\end{abstract}

\begin{abstract}
A rigorous analysis of the Merck-sponsored EST data with respect to known gene sequences increases the utility of the data set and helps refine methods for building a gene index. A highly curated human transcript data base was used as a reference data set of known genes. A detailed analysis of EST sequences derived from known genes was performed to assess the accuracy of EST sequence annotation. The EST data was screened to remove low-quality and low-complexity sequences. A set of high-quality ESTs similar to the transcript data base was identified using BLAST; this subset of ESTs was compared with the set of known genes using the Smith-Waterman algorithm. Error rates of several types were assessed based on a flexible match criterion defining sequence identity. The rate of lane-tracking errors is very low, $\sim 0.5 \%$. Insert size data is accurate within $\sim 20 \%$. Reversed clone and internal priming error rates are $\sim 5 \%$ and $2.5 \%$, respectively, contributing to the incorrect identification of reads as $3^{\prime}$ ends of genes. Follow-up investigation reveals that a significant number of clones, miscategorized as reversed, represent overlapping genes on the opposite strand of entries in the transcript data base. Relevance of these results to the creation of a high-quality index to the human genome capable of supporting diverse genomic investigations is discussed.
\end{abstract}

The random sequencing of cDNA clones has been used for more than a decade as a method for gene discovery (Costanzo et al. 1983). This technique more recently has been termed expressed sequence tag (EST) analysis, and has resulted in the partial characterization of a large variety of human genes (Adams et al. 1991, 1995; Wilcox et al. 1991; Khan et al. 1992; Okubo et al. 1992; Houlgatte et al. 1995), as well as those of other species (Waterson et al. 1992; Cooke et al. 1996). Significant effort has gone into EST sequencing; the majority of sequence entries found in the public data base GenBank (Benson et al. 1994) are the result of EST sequencing projects. However, aside from generalized estimates of numbers of genes represented and a quality-control analysis measuring levels of vector contamination and non-

\footnotetext{
'Corresponding author.

E-MAIL aaronson@merck.com; FAX (908) 594-2929.

${ }^{2}$ Current address: Bayer Corporation, Genomics Section, West Haven, Connecticut 06516.
}

nuclear RNA (Adams et al. 1995; Boguski and Schuler 1995; Aaronson and Elliston 1996), little is known about the nature of the data resulting from the automated, single-pass sequencing of cDNA clones.

In 1994, a public effort to generate both $5^{\prime}$ and $3^{\prime}$ EST sequences from the majority of human genes was developed (Williamson et al. 1995). This collaboration, consisting of Merck \& Co., Inc., the Integrated Molecular Analysis of Genomes and Their Expression (IMAGE) Consortium (Lennon et al. 1996), the Genome Sequencing Center (GSC) at Washington University of St. Louis School of Medicine, the National Center for Biotechnology Information (NCBI), and the Computational Biology and Informatics Laboratory (CBIL) at the University of Pennsylvania, has concentrated on the characterization of normalized libraries, and has produced more than 300,000 EST sequences from more than 180,000 IMAGE cDNA clones. These EST sequences com- 


\section{AARONSON ET AL.}

prise $>75 \%$ of publicly available human EST sequences. These sequences, derived from 27 distinct cDNA libraries, have been placed into the public EST data base dbEST (Boguski et al. 1993), as well as GenBank. The processing of these EST sequences has included quality assessment, contamination removal, and initial automated annotation, prior to their submission to the data base (Hillier et al., this issue). This annotation, including clone id, insert size, orientation, and endedness, provides important constraints governing the relationships between EST sequences and the clones from which they are derived, thereby greatly increasing the tractability of large-scale analyses of the data. A sufficient quantity of annotated EST data has been produced from the source libraries to assess both the accuracy of this annotation and the general nature of highthroughput EST data, with detailed statistics for each characterized library.

The characterization of sequence data that is generated from predominantly unknown transcription units is a difficult problem. However, the ESTs that are derived from known genes represented in public data bases can be readily studied. Analysis of human genes represented in GenBank has resulted in about 4000 characterized genes (UniGene, EGAD). Surveys of these genes have shown that $>60 \%$ are represented currently by one or more EST sequences (Adams et al. 1995; Boguski and Schuler 1995; White and Kerlavage 1996). These results are consistent with this study, which finds coverage of known genes to be over $62 \%$ (data not shown). A thorough comparison and analysis of the set of annotated EST sequences that are derived from these known genes can begin to elucidate the general nature of ESTs representing all human genes. As known genes have been subject to closer study, they provide a standard with which less reliable EST data can be compared. Such a comparison is the subject of this study, with the immediate goal of enhancing the utility of the Merck-sponsored data for the genomics community. The ultimate goal is the development of an index to the human genome (Merck Gene Index) that classifies each sequenced clone by both gene and transcript. A high-quality Gene Index can facilitate studies of gene expression, gene function, and the assessment of their relevance to human disease.

\section{EXPERIMENTAL DESIGN}

The detailed sequence analysis of the EST data was accomplished through a multistep process. First, a high-quality human transcript data base was identified for use in comparisons to partial transcript sequences. This provides a reference data set that can be used to study the nature of the ESTs that match these known genes. The choice of a transcript data base was limited to: (1) a set of transcript sequences culled from GenBank using annotated CDS, mRNA, and prim transcript features; (2) the UniGene (Boguski and Schuler 1995) data set developed at NCBI; and (3) EGAD (White and Kerlavage 1996), the Expressed Gene Anatomy Database developed at The Institute for Genomic Research. After careful consideration, EGAD was selected as the reference data set, because of its highly curated nature and the methods in which multiple transcripts for individual human genes are represented hierarchically. All known alternative splice forms are associated with each EGAD gene, and a sequence is given for each splice form. Next, the transcript data base was processed to remove artifacts, including vector sequences and redundant clone sequences. Searches were performed over the remaining transcripts in order to annotate coding region boundaries and locations of A-rich regions. In parallel, the EST data retrieved from GenBank was processed to remove low-quality sequence, using an "index quality" analysis. This analysis restricted the level of ambiguity allowed in sequences by truncating all sequences before they reach a level of $5 \% \mathrm{Ns}$, and removed all sequences less than $100 \mathrm{bp}$ in length. In addition, all sequences containing repeats were removed, in order to eliminate spurious matches as a result of alignments of repeat sequences during sequence comparison. This resulted in a data set of 175,666 sequences (as of December 15, 1995). Searches were performed over this index-quality data set to annotate positions of polyA signals. An initial comparison of the processed EGAD data set against these sequences was performed using BLAST (Altschul et al. 1990). This reduced the data to a set of sequences with sequence similarity to the known genes described in EGAD. Both the EGAD data and index-quality EST data were uploaded into a relational data base. At this point, a full SmithWaterman (Smith and Waterman 1981) comparison of the transcript data base and the BLASTselected ESTs was performed, and the results were stored in a relational data base for further analysis. The results presented are the summaries of this analysis. 


\section{AN ASSESSMENT OF HIGH-THROUGHPUT EST SEQUENCE DATA}

\section{RESULTS}

\section{Preprocessing of Data Sets}

The EGAD data base was analyzed for vector contamination and other artifacts prior to the full EGAD:EST analysis. One transcript, HT1138, was identified as containing vector and was removed from analysis. A screen for sequence redundancy yielded seven transcripts represented in both orientations. Each pair of transcripts was analyzed, and the appropriate entry removed (HT0464, HT1512, HT2417, HT2998, HT3667, HT4390, and HT4565). The final EGAD subset used for analysis represented 4412 transcripts (HTs) from 3970 genes (HGs).

In order to restrict the EST sequence analysis to high-quality portions of these single-pass sequences, several criteria were adopted to trim remaining poly(A) tails and screen low-quality sequence from the data set. To confine the analysis to the more reliable portions of each sequence read, each sequence was trimmed to contain only the high-quality portions of sequence, as annotated by GSC. Sequences of less than $100 \mathrm{bp}$ were removed, with a reduction of 20,165 entries. To further refine the set of sequences for analysis to high-quality reads, the ESTs were trimmed to reduce ambiguous base calls on the trailing end of reads. This was accomplished by truncating each read before the rate of Ns reached $5 \%$. A grace period of $99 \mathrm{bp}$ was allowed before the criterion was enforced, with 5253 sequences of less than 100 bp eliminated. Finally, to remove repetitive elements from the analysis, a set of 23,162 ESTs annotated in GenBank as containing repetitive sequence elements were eliminated from the remaining ESTs. This entire process reduced a set of 224,246 ESTs to a set of 175,666 of index-quality ESTs for further characterization. The results of the index-quality assessment are summarized by library in Table 1. Each library is characterized for the total number of EST sequences culled from dbEST, with the number of sequences passing the index-quality assessment indicated. The wide variation in library quality reported here may be caused by a number of factors, including library construction, sequence specific effects (e.g., high or low expression of GC-rich transcripts, high or low incidence of repeat sequence) or variations in sequencing protocol and reagents. Quality values range from $66.05 \%$ index-quality ESTs for Soares pineal gland N3HPG to $86.65 \%$ for Soares infant brain 1 NIB.

\section{Selection of EGAD-specific ESTs}

The detailed analysis of sequence similarities be-

\begin{tabular}{|lccl}
\hline \multicolumn{4}{l}{ Table 1. Results of Index Quality Screening } \\
\hline Library & ESTs & Index quality & Index quality (\%) \\
\hline Soares pineal gland N3HPG & 1,461 & 965 & 66.05 \\
Stratagene ovary & 3,146 & 2,135 & 67.86 \\
Stratagene lung (\#937210) & 8,172 & 5,741 & 70.25 \\
Weizmann Olfactory Epith. & 1,645 & 1,157 & 70.33 \\
Soares adult brain N2b5HB & 8,047 & 5,798 & 72.05 \\
Soares breast 3NbHBst & 9,530 & 6,903 & 72.43 \\
Soares adult brain N2b4HB & 4,406 & 3,260 & 73.99 \\
Stratagene liver & 8,417 & 6,245 & 74.20 \\
Soares fetal liver spleen & 70,463 & 52,649 & 74.72 \\
Soares retina N2b5HR & 2,303 & 1,734 & 75.29 \\
Soares retina N2b4HR & 4,043 & 3,045 & 75.32 \\
Soares breast 2NbHBst & 7,745 & 5,896 & 76.13 \\
Stratagene placenta & 3,640 & 2,790 & 76.65 \\
Stratagene fetal spleen & 6,263 & 4,979 & 79.50 \\
Soares ovary tumor NbHOT & 7955 & 633 & 79.62 \\
Soares melanocyte 2NbHM & 2,850 & 2,281 & 80.04 \\
Soares placenta 8 to 9 weeks & 1,345 & 1,090 & 81.04 \\
Soares placenta Nb2HP & 33,754 & 28,320 & 83.90 \\
Morton Fetal Cochlea & 1,609 & 1,389 & 86.33 \\
Soares infant brain 1NIB & 44,611 & 38,656 & 86.65 \\
\end{tabular}


tween known gene sequences and single-pass EST sequences requires the use of a rigorous pairwise alignment method, such as that of Smith and Waterman. However, the computational requirements of a full Smith-Waterman analysis of 4412 full-length transcript sequences against 175,666 ESTs were prohibitive. To reduce the matrix of comparison, a set of sequences similar to the transcript data base was selected by comparing each transcript with the refined EST data set using the rapid, but less sensitive, BLASTN program. In order to minimize false negatives, sequences meeting the modest criterion of $P \leqslant$ $10^{-30}$ were binned and subjected to the full Smith-Waterman comparison. A set of 42,668 ESTs was selected $\left(5^{\prime}, 58 \% ; 3^{\prime}, 42 \%\right)$, with an average processed size of $280 \mathrm{bp}\left(5^{\prime}, 281 \mathrm{bp} ; 3^{\prime}, 279\right.$ $\mathrm{bp})$, thus reducing the matrix of comparison by a factor of four, and reducing the calculation by an order of magnitude. The Smith-Waterman output was parsed into structured fields organized around individual searches and alignments, and the resulting tables were loaded into a relational data base.

\section{Identity Criteria and Reliability}

The detailed analysis of EST data that corresponds to known genes relies upon the definition of a sequence match. EST data by its nature is error prone, with the average sequence fidelity hovering around 97\% (Nishikawa and Nagai 1996). Members of highly conserved multigene families have regions that surpass 95\% identity, and often have regions of $99 \%$ or more identity (Efstratiadis et al. 1980). Thus, the choice of criteria for the determination of a match is important. Rather than arbitrarily choosing a single match criterion, these experiments were performed using three different criteria based upon the full-length of a Smith-Waterman optimal alignment: $95 \%$ identity over at least $100 \mathrm{bp}$, $97 \%$ identity over at least $100 \mathrm{bp}$, and 90\% identity over at least $200 \mathrm{bp}$. A rigorous definition of sequence match, while deserving of further study, is beyond the scope of this paper. The chosen criteria accommodate the observed sequence error in single-pass data, while providing stringent criteria for match determination. Evaluating the Smith-Waterman comparisons between EGAD and the 42,668 BLAST-selected ESTs with similarity to EGAD yielded sets of $36,593,32,413$, and 33,285 ESTs with identity to EGAD, accord- ing to each of the described criteria $(100 / 95,100 /$ 97 , and 200/90).

\section{Sequence Analysis}

\section{Reversed Clones/Mislabeled Ends}

The orientation of the inserts in cDNA cloning is determined by the biochemistry of the reversetranscription and cloning reactions. The libraries involved in this project were derived from oligo(dT) primed cDNA that was cloned in a unidirectional fashion (Soares et al. 1994). The sequencing was performed using distinct forward and reverse primers to generate $5^{\prime}$ and $3^{\prime}$ sequence, respectively. The association between primer and sequence must be maintained strictly in order to record the correct orientation of the insert. A failure in this process will result in the mislabeling of $5^{\prime}$ sequence as $3^{\prime}$, and $3^{\prime}$ sequence as $5^{\prime}$. Similarly, the cloning of the insert in the opposite orientation also will lead to the incorrect association of orientation and sequence, and therefore incorrect annotation of sequence. Since raw sequence is trimmed prior to GenBank submission, vector and poly(T) tracks that might distinguish $3^{\prime}$ from 5' ESTs are not present in the public data base. Our methodology does not discriminate between these two instances, hereafter referred to as reversed clones.

The orientation of the ESTs is encoded by the GSC in several ways in the public data bases. The primary method uses the $\mathrm{s} / \mathrm{r}$ primer notation in the suffix of the read id to encode $3^{\prime} / 5^{\prime}$. The secondary method encodes orientation using unstructured " 3 "' or " 5 "' labels in dbEST and GenBank flat-file entries. These two criteria should be in agreement for all EST sequences. However, $0.39 \%$ of entries studied (186 of the 46,668 BLAST-selected ESTs) have conflicting labels, indicating that errors occurred during annotation. Sequences are represented in the orientation that they are read from the sequencing gel; therefore, true 3 '-end sequences can be detected by identifying sequence matches to the noncoding, or strand. Conversely, true 5' - end sequences can be detected by identifying sequence matches to the coding, or + strand. Thus, true $3^{\prime}$ reads should match transcript sequences on the - strand, and true 5 ' reads should match transcript sequences on the + strand. A reversed clone is characterized by a true $5^{\prime}$ sequence that is labeled as $3^{\prime}$, and a true $3^{\prime}$ sequence that is labeled as $5^{\prime}$ (Fig. 1A). 
AN ASSESSMENT OF HIGH-THROUGHPUT EST SEQUENCE DATA
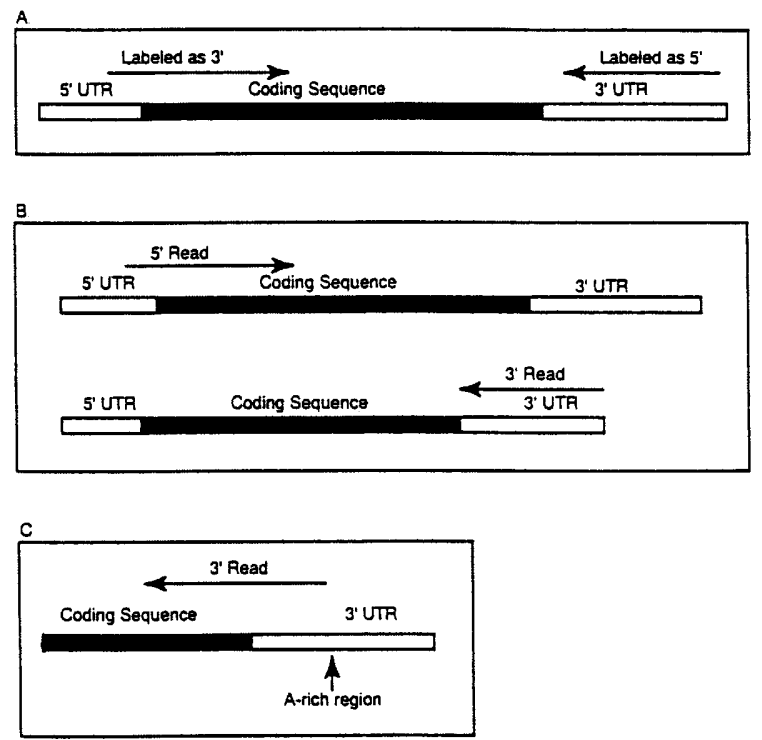

Figure 1 Idealized models for the analyses of EST sequences vs. EGAD transcripts are presented. $(A)$ An example of a reversed clone. The labeled 3' EST matches the transcript on the $(+)$ strand, and the labeled 5' EST matches the transcript on the $(-)$ strand. (B) An example of a lane-tracking error. The $5^{\prime}$ read and 3 ' read of a single clone do not match the same gene. (C) An example of an internal priming event. An A-rich region 20 bp upstream of the $3^{\prime}$ end of the EST is the source of internal priming during reverse transcription stage of library construction, resulting in a $3^{\prime}$ EST that is not anchored to the $\operatorname{poly}(A)$ tail.

The reversed clone analysis partitioned the set of EST clones that match known genes into three disjoint classes: (1) clone orientation agrees with EGAD (i.e., all ESTs from a clone that match EGAD agree in orientation); (2) clone orientation disagrees with EGAD (i.e., all ESTs from a clone that match EGAD disagree in orientation); and (3) clone orientation is mixed with respect to EGAD (i.e., the set of ESTs from a clone represent both orientations). The read id annotation was found to be more reliable and was used to specify clone orientation for this analysis. Summary totals are given in Table $2 \mathrm{~A}$ for the 3 match criteria. Over $5 \%$ of the EST clones are reversed in orientation with respect to EGAD, and only a few clones are in mixed orientation. Reversed clone rates for the 100/97 match criterion, organized by library, are given in Table 2B. The rates of reversed clones vary widely across libraries, from roughly $0.5 \%$ for a non-normalized fetal spleen library to $18 \%$ for normalized retina libraries. In general, the normalized (Soares) libraries have a higher rate of reversed clones than the nonnormalized libraries.

\section{Lane Tracking/Chimeric Clones}

A main concern in large-scale EST sequencing projects is maintaining the correct association of sequence to clone. To maintain this association, it is essential to correctly assign and track the individual lanes on the sequencing gels. Lanetracking errors introduce incorrect associations between sequence and clone. These can be identified more readily if there are multiple sequences associated with the same clone. Since both $5^{\prime}$ and 3 ' sequences have been determined for the majority of clones in this project, we can readily identify lane-tracking errors by first selecting a set of clones for which both $5^{\prime}$ and $3^{\prime}$ sequences are represented, and then identifying the subset where the $5^{\prime}$ sequence matches different genes than the 3 ' sequence. This method cannot distinguish between a lane tracking error and a chimeric clone; thus, they are not differentiated in this analysis. The resequencing, or full-length sequencing, of the affected clones could differentiate the rate of chimerism versus lane-tracking errors.

A set of clones was identified where both the 5' and $3^{\prime}$ reads matched a known transcript. Occasionally, a clone matched more than one transcript, as a result of either representation of multiple transcripts for the same gene or the presence of members of multigene families whose sequences are very highly conserved. This complication was resolved by comparing the sets of genes matching a clone's 5' read and 3' read, respectively, according to the three distinct match criteria, and then identifying those that had no gene in common (Fig. 1B). Summary statistics for each of the three match criteria are given in Table $3 \mathrm{~A}$, and a listing by library is given in Table $3 \mathrm{~B}$. The frequency of clones that exhibit lanetracking errors in the sample set is $\sim 1 \%$. Assuming that only one of these reads is incorrectly assigned, the rate of errors per sequence is approximately one-half the rate per clone, or $-0.5 \%$.

\section{Insert Size}

An important component of the Mercksponsored EST project is the estimation of insert sizes for each clone sequenced. Several tech- 
AARONSON EI AL.

Table 2. Comparison of ESTs

\begin{tabular}{|c|c|c|c|c|c|c|c|c|}
\hline & Clones & $\begin{array}{l}\text { Multiple } \\
\text { EST } \\
\text { clones }\end{array}$ & $\begin{array}{l}\text { Same } \\
\text { orien- } \\
\text { tation }\end{array}$ & $\begin{array}{l}\% \\
\text { Same }\end{array}$ & $\begin{array}{l}\text { Reverse } \\
\text { orien- } \\
\text { tation }\end{array}$ & $\begin{array}{l}\% \\
\text { Reversed }\end{array}$ & $\begin{array}{l}\text { Mixed } \\
\text { orien- } \\
\text { tation }\end{array}$ & $\begin{array}{l}\% \\
\text { Mixed }\end{array}$ \\
\hline \multicolumn{9}{|l|}{ Criteria } \\
\hline $100 / 95^{\mathrm{a}}$ & 25,919 & 10,647 & 24,546 & 94.70 & 1366 & 5.27 & 7 & 0.03 \\
\hline $100 / 97^{b}$ & 23,924 & 8,483 & 22,666 & 94.74 & 1253 & 5.24 & 5 & 0.02 \\
\hline $200 / 90^{c}$ & 24,309 & 8,969 & 23,051 & 94.82 & 1252 & 5.15 & 6 & 0.02 \\
\hline \multicolumn{9}{|l|}{ Library $^{d}$} \\
\hline \multicolumn{9}{|l|}{ Stratagene fetal } \\
\hline & 925 & 323 & 920 & 99.46 & 5 & 0.54 & 0 & 0.00 \\
\hline Stratagene liver & 2,092 & 697 & 2,075 & 99.19 & 16 & 0.76 & 1 & 0.05 \\
\hline \multicolumn{9}{|l|}{ Stratagene } \\
\hline \multicolumn{9}{|l|}{ Soares infant } \\
\hline brain 1NIB & 3,340 & 1,302 & 3,279 & 98.17 & 57 & 1.71 & 4 & 0.12 \\
\hline \multicolumn{9}{|l|}{ Morton Fetal } \\
\hline Cochlea & 219 & 117 & 214 & 97.72 & 5 & 2.28 & 0 & 0.00 \\
\hline $\begin{array}{l}\text { Soares fetal liver } \\
\text { spleen }\end{array}$ & 6,441 & 2,276 & 6,140 & 95.33 & 301 & 4.67 & 0 & 0.00 \\
\hline \multicolumn{9}{|l|}{ Weizmann } \\
\hline \multicolumn{9}{|l|}{ Olfactory } \\
\hline Epith. & 193 & 96 & 183 & 94.82 & 10 & 5.18 & 0 & 0.00 \\
\hline Stratagene lung & 971 & 374 & 918 & 94.54 & 53 & 5.46 & 0 & 0.00 \\
\hline \multicolumn{9}{|l|}{ Soares ovary } \\
\hline \multirow{2}{*}{\multicolumn{9}{|c|}{$\begin{array}{l}\text { Soares } \\
\text { melanocyte }\end{array}$}} \\
\hline & & & & & & & & \\
\hline $2 \mathrm{NbHM}$ & 222 & 77 & 207 & 93.24 & 15 & 6.76 & 0 & 0.00 \\
\hline \multicolumn{6}{|l|}{ Soares placenta 8} & & & \\
\hline to 9 weeks & 158 & 40 & 147 & 93.04 & 11 & 6.96 & 0 & 0.00 \\
\hline \multicolumn{9}{|l|}{ Soares breast } \\
\hline \multicolumn{9}{|l|}{ Soares placenta } \\
\hline $\mathrm{Nb} 2 \mathrm{Hp}$ & 3,956 & 1,637 & 3,643 & 92.09 & 313 & 7.91 & 0 & 0.00 \\
\hline Stratagene ovary & 555 & 233 & 511 & 92.07 & 44 & 7.93 & 0 & 0.00 \\
\hline \multicolumn{9}{|l|}{ Soares adult } \\
\hline \multirow{2}{*}{\multicolumn{8}{|c|}{ Soares adult }} & 0.00 \\
\hline brain N2b5HB & 820 & & & & & & & \\
\hline \multicolumn{9}{|l|}{ Soares breast } \\
\hline 2NbHBst & 873 & 235 & 783 & 89.69 & 90 & 10.31 & 0 & 0.00 \\
\hline \multicolumn{9}{|l|}{ Soares pineal } \\
\hline \multicolumn{9}{|l|}{$\begin{array}{l}\text { gland N3HPG } \\
\text { Soares retina }\end{array}$} \\
\hline N2b5HR & 167 & 43 & 137 & 82.04 & 30 & 17.96 & 0 & 0.00 \\
\hline \multicolumn{9}{|l|}{ Soares retina } \\
\hline $\mathrm{N} 2 \mathrm{~b} 4 \mathrm{HR}$ & 311 & 67 & 255 & 81.99 & 56 & 18.01 & 0 & 0.00 \\
\hline $\begin{array}{l}\text { Analysis of ESTs for reve } \\
\text { number of EST clones } \\
\text { number and percentage } \\
\text { EGAD are shown. } \\
\text { aAt least } 95 \% \text { identity o } \\
\text { bAt least } 97 \% \text { identity o } \\
\text { cAt least } 90 \% \text { identity o } \\
\text { d Results are shown for th }\end{array}$ & $\begin{array}{l}\text { ed or mislat } \\
\text { tching EGA } \\
\text { f EST clones } \\
\text { r } 100 \mathrm{bp} . \\
\text { r } 100 \mathrm{bp} . \\
200 \mathrm{bp} . \\
100 / 97 \mathrm{ma}\end{array}$ & clones & one by & $\begin{array}{l}\text { arin } \\
\text { sw } \\
\text { re }\end{array}$ & ien & $\begin{array}{l}\text { he EGA } \\
\text { EST ma } \\
\text { d mixe }\end{array}$ & $\begin{array}{l}\text { ript } \\
\text { GAD } \\
\text { tion }\end{array}$ & $\begin{array}{l}\text { base. The } \\
\text { sted. The } \\
\text { respect to }\end{array}$ \\
\hline
\end{tabular}


AN ASSESSMENT OF HIGH-THROUGHPUT EST SEQUENCE DATA

Table 3. Analysis of Lane-tracking Errors

\begin{tabular}{lrrc}
\hline & Clones & Clones with error & \% Clones with error \\
\hline Criteria $^{\text {a }}$ & & & \\
$100 / 95$ & 10,635 & 101 & 0.95 \\
$100 / 97$ & 8,474 & 78 & 0.92 \\
$200 / 90$ & 8,959 & 92 & 1.03 \\
& & & \\
Library & & & 0.00 \\
Soares adult brain N2b5HB & 241 & 0 & 0.00 \\
Morton Fetal Cochlea & 117 & 0 & 0.00 \\
Weizmann Olfactory Epith. & 96 & 0 & 0.00 \\
Soares melanocyte 2NbHM & 77 & 0 & 0.00 \\
Soares retina N2b5HR & 43 & 0 & 0.00 \\
Soares ovary tumor NbHOT & 33 & 0 & 0.53 \\
Soares pineal gland N3HPG & 24 & 0 & 0.73 \\
Stratagene placenta & 286 & 1 & 0.99 \\
Soares fetal liver spleen & 2,276 & 12 & 1.07 \\
Soares placenta Nb2HP & 1,636 & 12 & 1.28 \\
Soares breast 3NbHBst & 303 & 3 & 1.28 \\
Stratagene lung & 374 & 4 & 1.29 \\
Soares breast 2NbHBst & 235 & 3 & 1.49 \\
Soares adult brain N2b4HB & 78 & 1 & 1.55 \\
Stratagene ovary & 233 & 3 & 2.16 \\
Soares infant brain 1NIB & 1,296 & 17 & 2.50 \\
Soares retina N2b4HR & 67 & 1 & \\
Stratagene fetal spleen & 323 & 5 & \\
Stratagene liver & 696 & 15 & \\
Soares placenta 8 to 9 weeks & 40 & 1 & \\
\hline Number of clones having both a 3' and 5' read matching EGAD are shown, as are the number and percentage \\
of those clones showing a lane-tracking error. & & \\
aCriteria as in Table 2. & & & \\
bResults are shown for the 100/97 match criterion. & & \\
\hline
\end{tabular}

niques have been used to estimate insert size, including PCR and restriction digestion (Hillier et al., this issue). The insert length for a clone can be calculated if both a $3^{\prime}$ read and a $5^{\prime}$ read are available and match a known transcript sequence. The alignments determine the extent of the transcript corresponding to the clone, and from this, the true insert size of the clone can be calculated. This method is complicated by the presence of alternative splice forms of genes, as well as by closely related members of gene families. Associating a clone with a related but distinct transcript will invalidate the result. Thus, clones whose sequences matched more than one transcript were excluded. Clones whose sequences appeared to be inappropriately trimmed were also removed. The possibility of underestimating the actual insert size was investigated by limiting the analysis to ESTs whose leading (5') end was included in the EGAD alignment. Introducing this constraint did not affect the results significantly, and, therefore, it was not enforced in the final analysis. Summary statistics of insert sizes for each of the three match criteria are given in Table 4A. The average insert size of sequenced clones is $-0.9 \mathrm{~kb}$; the average error in insert size determination is about $21.5 \%$, where error refers to the difference between calculated and reported insert size, expressed as a percentage of the calculated size. Results organized by library are shown in Table $4 \mathrm{~B}$, according to the $100 / 97$ match criterion.

\section{Internal Priming/Alternative Termination}

The development of a nonredundant set of clones representing all of the transcripts characterized in the EST project relies upon analysis of comparable regions of $3^{\prime}$ untranslated region 
Table 4. Results of Insert-size Analysis

\begin{tabular}{|c|c|c|c|c|c|c|}
\hline & Clones & $\begin{array}{l}\text { Average } \\
\text { reported } \\
\text { size }\end{array}$ & $\begin{array}{l}\text { Average } \\
\text { calculated } \\
\text { size }\end{array}$ & $\begin{array}{l}\text { Minimum } \\
\text { difference } \\
(\%)\end{array}$ & $\begin{array}{l}\text { Maximum } \\
\text { difference } \\
(\%)\end{array}$ & $\begin{array}{l}\text { Average } \\
\text { difference } \\
(\%)\end{array}$ \\
\hline \multicolumn{7}{|l|}{ Criteria $^{a}$} \\
\hline $100 / 95$ & 7664 & 979 & 890 & 0.00 & 523.25 & 21.78 \\
\hline $100 / 97$ & 6197 & 988 & 901 & 0.00 & 500.54 & 21.41 \\
\hline $200 / 90$ & 6296 & 971 & 886 & 0.00 & 523.25 & 21.37 \\
\hline \multicolumn{7}{|l|}{ Library $^{b}$} \\
\hline Soares retina N2b4HR & 11 & 1666 & 1476 & 1.82 & 22.81 & 15.22 \\
\hline Soares adult brain N2b4HB & 62 & 1469 & 1321 & 2.49 & 107.71 & 18.18 \\
\hline Soares infant brain 1 NIB & 1028 & 1605 & 1439 & 0.07 & 307.91 & 18.71 \\
\hline Soares breast $3 \mathrm{NbHBst}$ & 266 & 876 & 772 & 0.36 & 128.97 & 19.01 \\
\hline Soares breast $2 \mathrm{NbHBst}$ & 184 & 868 & 760 & 0.28 & 177.86 & 19.11 \\
\hline Stratagene fetal spleen & 245 & 803 & 733 & 0.09 & 135.61 & 19.42 \\
\hline Soares fetal liver spleen & 1844 & 959 & 853 & 0.00 & 500.54 & 19.92 \\
\hline Soares placenta $\mathrm{Nb} 2 \mathrm{HP}$ & 1404 & 843 & 753 & 0.00 & 444.82 & 19.98 \\
\hline Soares adult brain $\mathrm{N} 2 \mathrm{~b} 5 \mathrm{HB}$ & 210 & 780 & 675 & 0.77 & 172.29 & 20.36 \\
\hline Soares retina $\mathrm{N} 2 \mathrm{~b} 5 \mathrm{HR}$ & 7 & 867 & 738 & 4.84 & 75.67 & 22.94 \\
\hline Soares pineal gland N3HPG & 14 & 940 & 900 & 2.85 & 57.28 & 23.02 \\
\hline Weizmann Olfactory Epith. & 43 & 834 & 669 & 1.34 & 138.40 & 24.09 \\
\hline Soares ovary tumor $\mathrm{NbHOT}$ & 21 & 894 & 722 & 2.77 & 99.20 & 25.20 \\
\hline Stratagene placenta & 188 & 791 & 748 & 0.09 & 305.96 & 27.77 \\
\hline Stratagene lung & 224 & 648 & 689 & 0.43 & 113.32 & 30.06 \\
\hline Stratagene ovary & 129 & 512 & 458 & 0.78 & 379.53 & 30.74 \\
\hline Stratagene liver & 317 & 703 & 931 & 0.22 & 139.68 & 37.24 \\
\hline
\end{tabular}

(UTR) sequence. This analysis is fundamental to the initial development of the Merck Gene Index, as it provides a classification of expressed sequence into transcript equivalence-classes. The $3^{\prime}$ UTR region is the most diverse region of transcripts (Ko et al. 1994), and each 3' UTR fragment can serve as a unique identifier for its source transcript. All 3' UTR fragments resulting from 3' reads are anchored at the poly $(\mathrm{A})$ site, as they are primed by an oligo(dT) primer at the poly(A) tail and therefore are directly comparable. A potential problem with this approach is the occurrence of false 3 ' ends because of internal priming. This can occur during library construction as a result of priming from A-rich regions upstream of the poly(A) tail during the reverse transcription process, which results in $3^{\prime}$ ends that are not anchored to the poly(A) site (Fig. 1C).

To assess the level of internal priming, the set of $3^{\prime}$ ESTs matching known transcripts were ana- lyzed to determine whether or not they fall at the $3^{\prime}$ end of transcripts. ESTs that fall close to the end of a transcript are considered to have been primed correctly; ESTs that only fall upstream of the poly(A) site may result from either an alternative 3 ' end or an internal priming event. Since internal priming should occur from a region similar to the oligo(dT) primer, an attempt was made to distinguish these events by looking for canonical signals characteristic of $3^{\prime}$ ends, and A-rich regions that can serve as a template for oligo(dT)-primed cDNA synthesis. ESTs that do not fall at the $3^{\prime}$ end are classified as: (1) internal ESTs with canonical poly(A) signals, suggestive of an alternative $3^{\prime}$ end; (2) internal ESTs that lack canonical poly(A) signals and are proximal to an A-rich region, considered likely to be the result of internal priming; or (3) internal ESTs that lack canonical poly(A) signals that are not proximal to an A-rich region. These ESTs may be derived 


\section{AN ASSESSMENT OF HIGH-THROUGHPUT EST SEQUENCE DATA}

from true 3 ' ends that lack a canonical poly(A) signal or may be the result of an internal priming event not captured by the A-rich criteria defined in this analysis. Therefore, no judgment was made as to the import of this latter class. A threshold of $20 \mathrm{bp}$ was used for determining whether an EST was proximal to the end of a transcript. Two values, $20 \mathrm{bp}$ and $50 \mathrm{bp}$, in turn, were used for determining whether an EST was positioned appropriately with respect to an Arich region. Summary statistics for the three match criteria are given in Table 5A. The overall level of internal priming as measured by these criteria is relatively low, within the range of $2-3 \%$. The rate of internal priming varies considerably by library: Several libraries have rates greater than 3\% (Table 5B).

\section{DISCUSSION}

A gene index is ideally a collection of information about genes in which all the information pertaining to a particular gene is organized into a single gene class, and each gene class is distinct from all other gene classes. The partial and errorprone nature of EST data complicates the definition and formulation of the set of gene classes that form an index. Moreover, there are many reasonable characterizations of a gene index, driven by different intended uses of the information. The Merck Gene Index is intended to be an informatics resource for the community, designed to facilitate diverse and comprehensive investigations into the nature of the human genome, including studies of gene mapping, gene expression, and gene function. Such disparate endeavors require a flexible index that can generate a varied set of reports designed to address the specific needs of each investigation, reflecting the particular scientific assumptions and goals of individual researchers. This can be accomplished by creating a data base that one can query that represents explicitly the relationships between EST sequences and other relevant data, and a sophisticated indexing methodology capable of producing targeted reports satisfying the criteria specified in the query.

This study has made significant steps toward the development of a dynamic gene index in several ways. First, levels of accuracy have been established for important annotation to the majority of public human EST sequences, thereby enabling individuals to make informed decisions on the extent to which they will rely upon the an- notations. A background rate of biological and informatics errors is unavoidable in large-scale sequencing projects. Moreover, the error rates will naturally change in response to applications of different technology, improvements in methodology, and an evolving understanding of the underlying biology. To perform effectively in this noisy environment, it is imperative that confidence levels be established and analytical methodology be developed that can withstand violating the constraints imposed by the annotations.

Second, the development of a flexible data repository that will be the foundation of the Merck Gene Index has begun. A relational representation of annotated EST sequence data, annotated transcript data, and sequence similarity search results provides the basis for these analyses. Parameterized queries over this data are employed, granting flexibility in choosing criteria governing aspects of these analyses. A flexible methodology is crucial in order to (1) provide robustness and maintain relevance in the emerging field of genomic science, and (2) enable basic research into the nature of the genome, by providing a framework in which hypotheses can be tested and poorly understood or unknown biological phenomena can be explored.

Third, a multilevel sequence comparison strategy has been adopted, utilizing the BLAST algorithm to rapidly discriminate sequences that are clearly too dissimilar to be identical, and employing the rigorous Smith-Waterman algorithm to distinguish similarity from identity. The initial development of the Gene Index depends upon binning EST clones into transcript equivalence classes, based upon sequence comparisons of error-prone single-pass EST data. By using BLAST to quickly screen out dissimilar sequences, a reduced set of comparisons can be performed via the computationally intensive Smith-Waterman algorithm, focusing greater sensitivity on the difficult problem of discerning identity from similarity using EST data.

The detailed analysis of EST data begins to provide feedback about the accuracy of annotations attached to EST sequence. Specifically, this analysis has evaluated clone id, insert size, orientation, and endedness. The correct association of $5^{\prime}$ reads with corresponding 3 ' reads using the GSC clone id has been assessed through lanetracking. The rate of sequences exhibiting lanetracking errors is $\sim 0.5 \%$, indicating that the mapping from sequence to clone is of high fidelity. This has two important implications. First, physi- 
AARONSON ET AL.

Table 5. Internal Priming Analysis Results

\begin{tabular}{|c|c|c|c|c|c|c|c|c|c|}
\hline & & $\begin{array}{l}(-) \\
\text { Strand } \\
\text { ESTs }^{b}\end{array}$ & $\begin{array}{l}\text { Internal to } \\
\text { transcript }^{c}\end{array}$ & $\begin{array}{l}\% \\
\text { Internal }\end{array}$ & $\begin{array}{l}\text { Internal } \\
\text { with } \\
\text { poly }(A)^{d}\end{array}$ & $\begin{array}{l}\% \text { Internal } \\
\text { with poly(A) }\end{array}$ & $\begin{array}{l}\text { Internal } \\
\text { without } \\
\text { poly(A) }\end{array}$ & $\begin{array}{l}\text { Internal } \\
\text { priming }^{\mathrm{e}}\end{array}$ & $\begin{array}{l}\% \\
\text { Internal } \\
\text { priming }\end{array}$ \\
\hline \multicolumn{10}{|l|}{ Criteria $^{a}$} \\
\hline $100 / 95$ & & 15,558 & 1815 & 11.67 & 723 & 39.83 & 1092 & & \\
\hline & $\begin{array}{l}20 \\
50\end{array}$ & & & & & & & $\begin{array}{l}339 \\
406\end{array}$ & $\begin{array}{l}2.18 \\
2.61\end{array}$ \\
\hline $100 / 97$ & $\begin{array}{l}20 \\
50\end{array}$ & 13,324 & 1682 & 12.62 & 665 & 39.54 & 1017 & $\begin{array}{l}333 \\
399\end{array}$ & $\begin{array}{l}2.50 \\
2.99\end{array}$ \\
\hline $200 / 90$ & $\begin{array}{l}20 \\
50\end{array}$ & 13,792 & 1785 & 12.94 & 718 & 40.22 & 1067 & $\begin{array}{l}337 \\
404\end{array}$ & $\begin{array}{l}2.44 \\
2.93\end{array}$ \\
\hline \multicolumn{10}{|l|}{$\begin{array}{l}\text { Library }^{f} \\
\quad \text { Soares melan }\end{array}$} \\
\hline $\begin{array}{l}2 \mathrm{NbHM} \\
\text { Soares placenta } 8\end{array}$ & & 114 & 16 & 14.04 & 3 & 18.75 & 13 & 0 & 0.00 \\
\hline to 9 weeks & & 78 & 9 & 11.54 & 2 & 22.22 & 7 & 0 & 0.00 \\
\hline Stratagene ovary & & 367 & 22 & 5.99 & 10 & 45.45 & 12 & 2 & 0.54 \\
\hline $\begin{array}{l}\text { Stratagene lung } \\
\text { Soares adult brain }\end{array}$ & & 579 & 61 & 10.54 & 31 & 50.82 & 30 & 4 & 0.69 \\
\hline $\begin{array}{l}\mathrm{N} 2 \mathrm{~b} 5 \mathrm{HB} \\
\text { Soares breast }\end{array}$ & & 412 & 67 & 16.26 & 24 & 35.82 & 43 & 5 & 1.21 \\
\hline $\begin{array}{c}3 \mathrm{NbHBst} \\
\text { Soares retina }\end{array}$ & & 574 & 55 & 9.58 & 14 & 25.45 & 41 & 7 & 1.22 \\
\hline $\begin{array}{l}\text { N2b4HR } \\
\text { Weizmann }\end{array}$ & & 159 & 39 & 24.53 & 6 & 15.38 & 33 & 2 & 1.26 \\
\hline $\begin{array}{l}\text { Olfactory Epith. } \\
\text { Soares placenta }\end{array}$ & & 132 & 17 & 12.88 & 5 & 29.41 & 12 & 2 & 1.52 \\
\hline $\begin{array}{c}\mathrm{Nb} 2 \mathrm{HP} \\
\text { Soares breast }\end{array}$ & & 2,178 & 236 & 10.84 & 90 & 38.14 & 146 & 37 & 1.70 \\
\hline $\begin{array}{l}2 \mathrm{NbHBst} \\
\text { Soares adult brain }\end{array}$ & & 406 & 48 & 11.82 & 9 & 18.75 & 39 & 8 & 1.97 \\
\hline $\begin{array}{l}\mathrm{N} 2 \mathrm{~b} 4 \mathrm{HB} \\
\text { Stratagene }\end{array}$ & & 184 & 18 & 9.78 & 4 & 22.22 & 14 & 4 & 2.17 \\
\hline $\begin{array}{l}\text { placenta } \\
\text { Stratagene fetal }\end{array}$ & & 435 & 44 & 10.11 & 21 & 47.73 & 23 & 10 & 2.30 \\
\hline $\begin{array}{l}\text { spleen } \\
\text { Soares infant brain }\end{array}$ & & 624 & 87 & 13.94 & 65 & 74.71 & 22 & 15 & 2.40 \\
\hline $\begin{array}{l}1 \text { NIB } \\
\text { Soares retina }\end{array}$ & & 1,995 & 244 & 12.23 & 128 & 52.46 & 116 & 50 & 2.51 \\
\hline $\begin{array}{c}\text { N2b5HR } \\
\text { Soares ovary }\end{array}$ & & 73 & 16 & 21.92 & 4 & 25.00 & 12 & 2 & 2.74 \\
\hline $\begin{array}{l}\text { tumor NbHOT } \\
\text { Soares fetal liver }\end{array}$ & & 71 & 9 & 12.68 & 3 & 33.33 & 6 & 2 & 2.82 \\
\hline $\begin{array}{l}\text { spleen } \\
\text { Morton Fetal }\end{array}$ & & 3,607 & 444 & 12.31 & 166 & 37.39 & 278 & 128 & 3.55 \\
\hline Cochlea & & 128 & 24 & 18.75 & 10 & 41.67 & 14 & 5 & 3.91 \\
\hline $\begin{array}{l}\text { Stratagene liver } \\
\text { Soares pineal }\end{array}$ & & 1,165 & 213 & 18.28 & 70 & 32.86 & 143 & 47 & 4.03 \\
\hline gland N3HPG & & 43 & 13 & 30.23 & 0 & 0.00 & 13 & 3 & 6.98 \\
\hline \multicolumn{10}{|c|}{$\begin{array}{l}\text { 'The summary lists the number of ESTs that are within } 20 \text { or } 50 \mathrm{bp} \text { of an appropriate A-rich region, with results for each of the three } \\
\text { match criteria implemented. Criteria as in Table } 2 \text {. } \\
\text { bNumber of true 3' ESTs (sequences that match the - strand of transcripts). } \\
\text { ' } 3 \text { ' ESTs that do not align within } 20 \mathrm{bp} \text { upstream of the reported } 3 \text { ' end of transcripts. } \\
\text { 'Internal ESTs that contain a canonical poly(A) signal. } \\
\text { 'Internal ESTs that do not contain a poly(A) signal and are proximal to an A-rich region that could act as a template for priming } \\
\text { by an oligo(dT) primer. } \\
\text { f Results are shown for the } 20 \mathrm{bp} \text { and } 100 / 97 \text { match criteria. }\end{array}$} \\
\hline
\end{tabular}


cal clones identified through sequence similarity can be reliably retrieved. Second, all sequences annotated with the same clone id are derived from the same transcript. This is of great utility for the construction of an index to the genome, which exploits sequence identity to categorize all clones representing a single transcript (or gene) into a single index class.

Accurate insert size data for EST clones enables the selection of the longest clone from each index class, and is a valuable aid to performing sequence assemblies within a class. However, the insert size analysis has shown this data to be accurate only within $-20 \%$ - the average error rate of reported insert sizes is about $21 \%$ overall, and exceeds $15 \%$ for each library. This complicates the use of insert size data in building contigs and the development of index classes. However, because the average error over most of the clones falls in the $15-20 \%$ range, a systematic, and therefore correctable, error during insert size determination may be responsible. Differing techniques used to determine insert size may account for the differences observed among libraries, as may the differential presence of alternatively spliced transcripts in various tissues.

Reversed clones and internal priming events each contribute to the incorrect identification of sequences as $3^{\prime}$ ends of genes, and to the reduction in fidelity of an index that relies upon annotated 3' ends to categorize clones. This study estimates the level of reversed clones in the EST data set to be $-5 \%$ overall, and the rate of internal priming to be $2-3 \%$. An initial investigation into a small sample of identified reversed clones indicates that a match on the wrong strand is not sufficient to categorize a clone as reversed, and suggests that real transcripts identified as reversed clones may have been removed while preprocessing EGAD. A significant number of these opposite strand matches result from genes overlapping in the opposite orientation. This phenomenon also has been reported elsewhere (Houlgatte et al. 1995), suggesting that overlapping genes is not a rare occurrence. A rigorous analysis of the extent of this phenomenon is imperative, and methodology must be developed in order to avoid merging distinct, overlapping genes into an index class.

\section{METHODS}

\section{EGAD-EST Comparisons}

Bioccelerator (Compugen 1995) caches were built from
FastA (Pearson 1991)-formatted versions of EGAD transcripts and EST data, using the bic_makecache command. Each of the 4420 EGAD transcripts was searched against the set of 42,668 ESTs, using a (two-stranded) multiquery Smith-Waterman search on a four-board Biocellerator-2, with gap creation and extension penalties of 4.50 and 0.05 , respectively. Parameters used were listsize $=200$, gapweight $=4.50$, length $=0.05$, minlist $=2.50$, minseq $=2$, noaverage, and nonormalize. The scoring matrix used sets all matches to 1 , all mismatches to -0.6 and all Ns (fourway ambiguities) to 0 . Alignments were done as a postprocessing step with the identical parameters, using the program bic_align. Alignments for the top 100 hits were performed. If the 100th alignment was judged significant according to any of the three match criteria, an additional 100 alignments were performed.

\section{Uploading Search Results to Sybase}

A Perl (Wall and Schwartz 1992) script was run over search and alignment output files, building bulk copy files suitable for direct upload of the search and alignment results into Sybase (Sybase 1994) tables. Tables were uploaded through the Sybase bcp utility.

\section{Preprocessing of Transcript Data Base}

The EGAD data base was screened for the cmvsport, arbl2skm, lt $7 \mathrm{t} 3 \mathrm{~d}-\mathrm{pac}$, and lafmid vectors (WebMaster 1996), using the Smith-Waterman algorithm. Searches were run on the Biocellerator using the parameters gapweight $=5.00$, length $=0.30$, minlist $=2.50$, minseq $=2$, noaverage, and nonormalize. HT1138 was identified as contaminated by cmvsport $($ ZScore $=16.08)$ and was eliminated from the data set.

The EGAD data base was screened for redundant clones by examining pairs of transcripts that strongly matched the same EST on different strands. Seven pairs were identified in this manner: HT0464-HT4215, HT1512HT4343, HT2417-HT3615, HT2998-HT4551, HT3391HT3667, HT2896-HT4390, and HT3183-HT4565. The overlap region of the pair was computed using the GCG (Genetics Computer Group 1994) bestfit program, and used to query the nonredundant nucleotide data base Merck.DNA (Blevins et al. 1995) using BLAST. The BLAST reports were analyzed to ascertain the correct orientation of each clone. The member of each pair corresponding to the likely incorrect orientation was eliminated from the data set (HT0464, HT1512, HT2417, HT2998, HT3667, HT4390, and HT4565).

\section{Relational Representation of Data}

\section{Genes, Transcripts, ESTs, and Alignments}

A relational data-base schema was created to represent EGAD, ESTs, and the results of the Smith-Waterman alignments. This enabled queries to be performed against both the EGAD data and the alignment results. An Extended Entity Relationship diagram (Chen 1976) for the schema is given in Figure 2. The central concepts are EGAD genes and transcripts, ESTs, and alignments between them, rep- 
AARONSON ET AL.

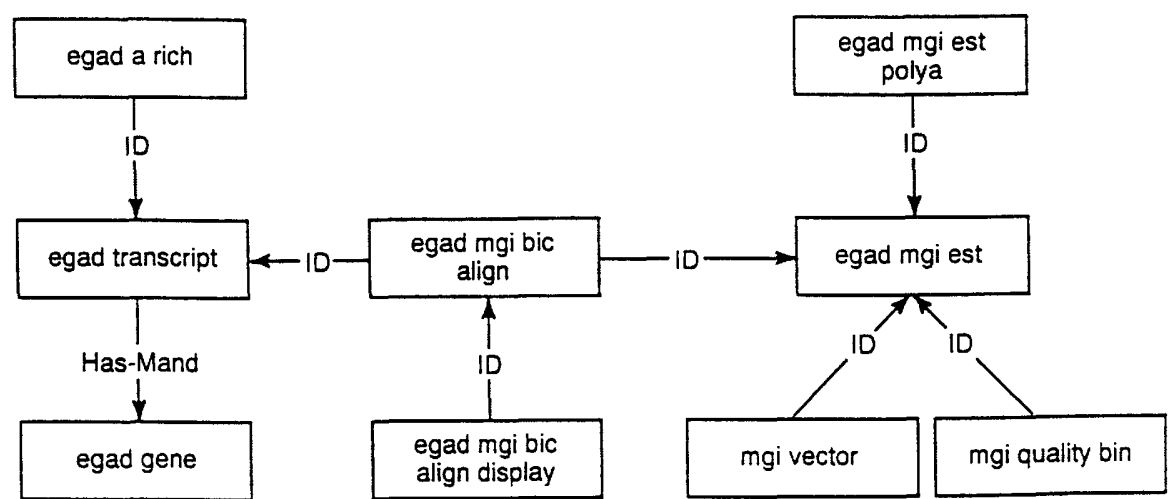

Figure 2 Schema for tables used in analysis. The diagram was drawn using ERDRAW (Szeto and Markowitz 1993). In these schemas Has arcs are many-toone in the direction of the arrows; the suffix -Mand on an arc label designates that the relationship is mandatory. An ID arc, also many-to-one in the direction of the arrow, denotes that the primary key of the "one" table forms part of the primary key of the "many" table.

resented by the egad gene, egad transcript, egad mgi_est, and egad_mgi_bic_align tables, respectively. Detailed descriptions of these tables are given in Table 6 . There can be many transcripts for a single gene, representing alternative splicing. Most of the information in the gene and transcript tables came from EGAD, with the exception of three columns which were added to the egad transcript table: cds_start, cds_end, and cap_topolya. Values for the cds length column were recalculated from cds_start and cds_end values. The alignment displays were stored in a separate table, egad mgi_bic_align display, to maximize efficiency of querying the alignment results. All calculated alignments were stored.

\section{Identifying Index Quality EST Sequence}

The results of the quality screening were stored in the mgi_quality_bin table. Each accession was assigned a quality code. Possible values are: $1=$ too short by GSC's standards; $2=$ too short by Merck's standards; $3=$ marked by NCBI as containing repeat sequence; $4=$ index quality. Counts of ESTs in each category can be obtained by executing a simple query in the Structured Query Language (SQL) relational data-base language.

\section{Poly(A) Signals in ESTS}

To annotate ESTs for the presence or absence of poly(A) signals, a simple string search was used to identify the presence of three canonical poly(A) signals (AATAAA, ATTAAA, and AATAAT; Birnstiel et al. 1985) within 35 bp of the leading end of all EST sequences. Based on the sequencing methodology, the signals are represented on the opposite strand; therefore, the reverse complement of each signal was utilized in the search (TTTATT, TTTAAT, and ATTATT). The signal type and the offset within the nucleotide sequence were stored in the egad_mgi est polya table. A sequence could have many poly $(\bar{A})$ signals. A null offset was used to designate that no poly(A) signal was found within the 35-bp window. This table was used in queries as follows: An EST with accession number a has a poly(A) signal if there is a row in the egad_mgi_est polya table with accession $=\mathbf{a}$ and non-null offset.

\section{A-rich Regions of Transcripts}

Two different indicators of Arich regions were used: (1) 6 consecutive A's present, and (2) 14 A's present within 18 consecutive bases. A-rich regions within EGAD transcripts were identified via a Perl script utilizing these criteria. The starting and ending positions of the Arich regions within the transcript sequence were recorded in the startpos and endpos columns of the egad a rich table, along with an integer code representing the relevant indicator. A transcript could have many A-rich regions.

\section{Coding Region Boundaries}

Coding region boundaries were derived for EGAD transcripts by identifying the protein coding region of the transcript. This was done through a Perl script. The starting and ending boundaries were recorded in the cds start and cds end columns of the egad transcript table; the length of the coding sequence was recalculated and recorded in the column cds length. In some instances, EGAD did not associate a protein sequence with a transcript, or the nucleotide sequence included no region that could code for the given protein. In these cases, null values were recorded for the cds start, cds end, and cdslength columns. In all cases where a coding region could be determined, however, it was unique.

\section{cap-to-poly(A) length}

The poly(A) site was determined for each EGAD transcript as the last base prior to the poly(A) tail. The length of the transcript from the 5 ' end to this site was recorded in the cap_to polya column in the egad transcript table. If a transcript lacked a poly (A) tail, cap_to polya was set to the EGAD transcript length. For increased accuracy in analyses involving the 3' end of the EGAD transcript, the cap to polya length was used instead of the actual EGAD transcript length.

\section{Vector Contamination}

EGAD transcripts were screened for vector as described. For all hits, the Zscore and an integer code representing the vector type were recorded in the mgi vector table, which is in a many-to-one relationship to egad_transcript. If 
AN ASSESSMENT OF HIGH-THROUGHPUT EST SEQUENCE DATA

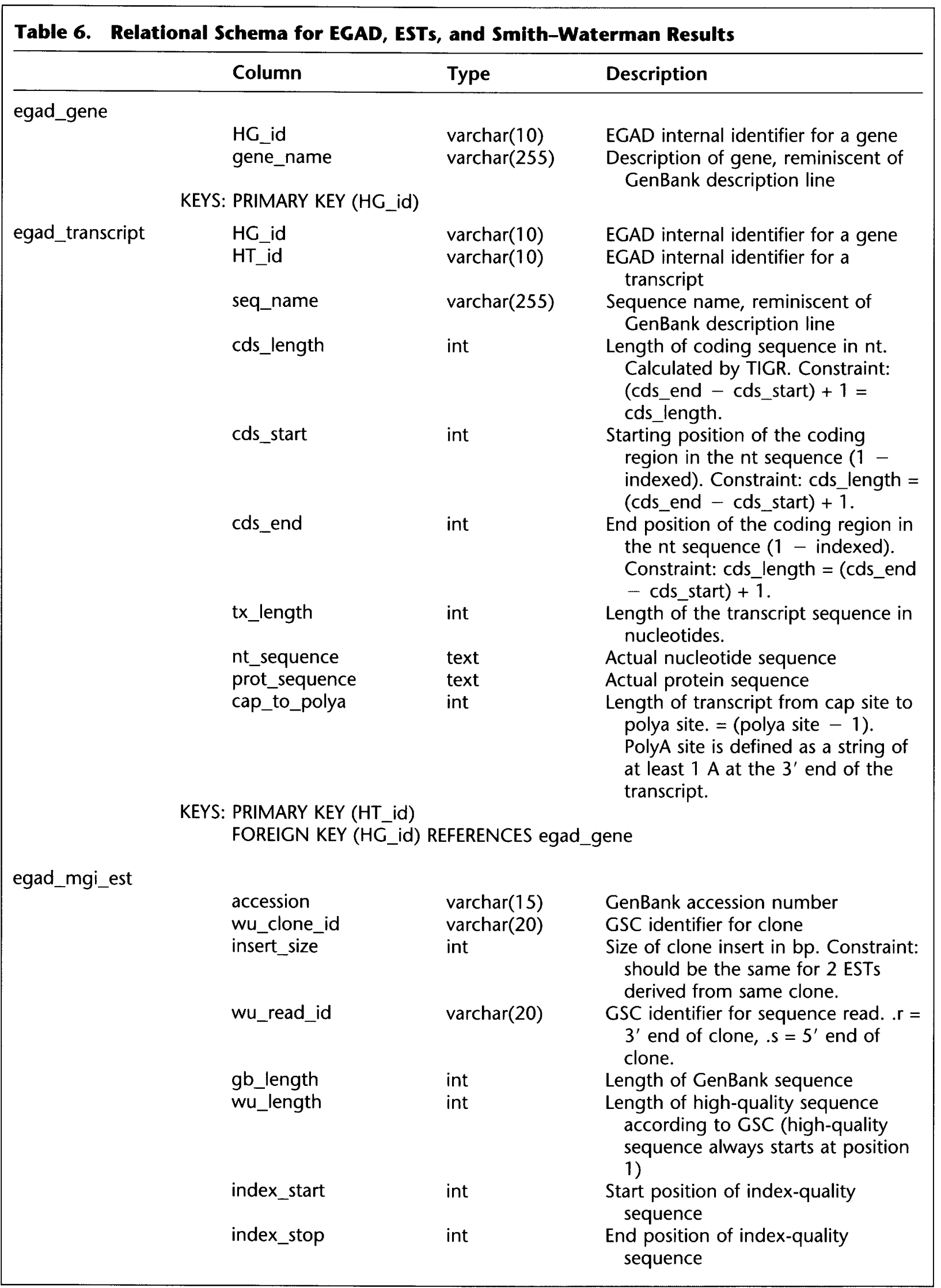


AARONSON EI AL.

Table 6. (Continued)

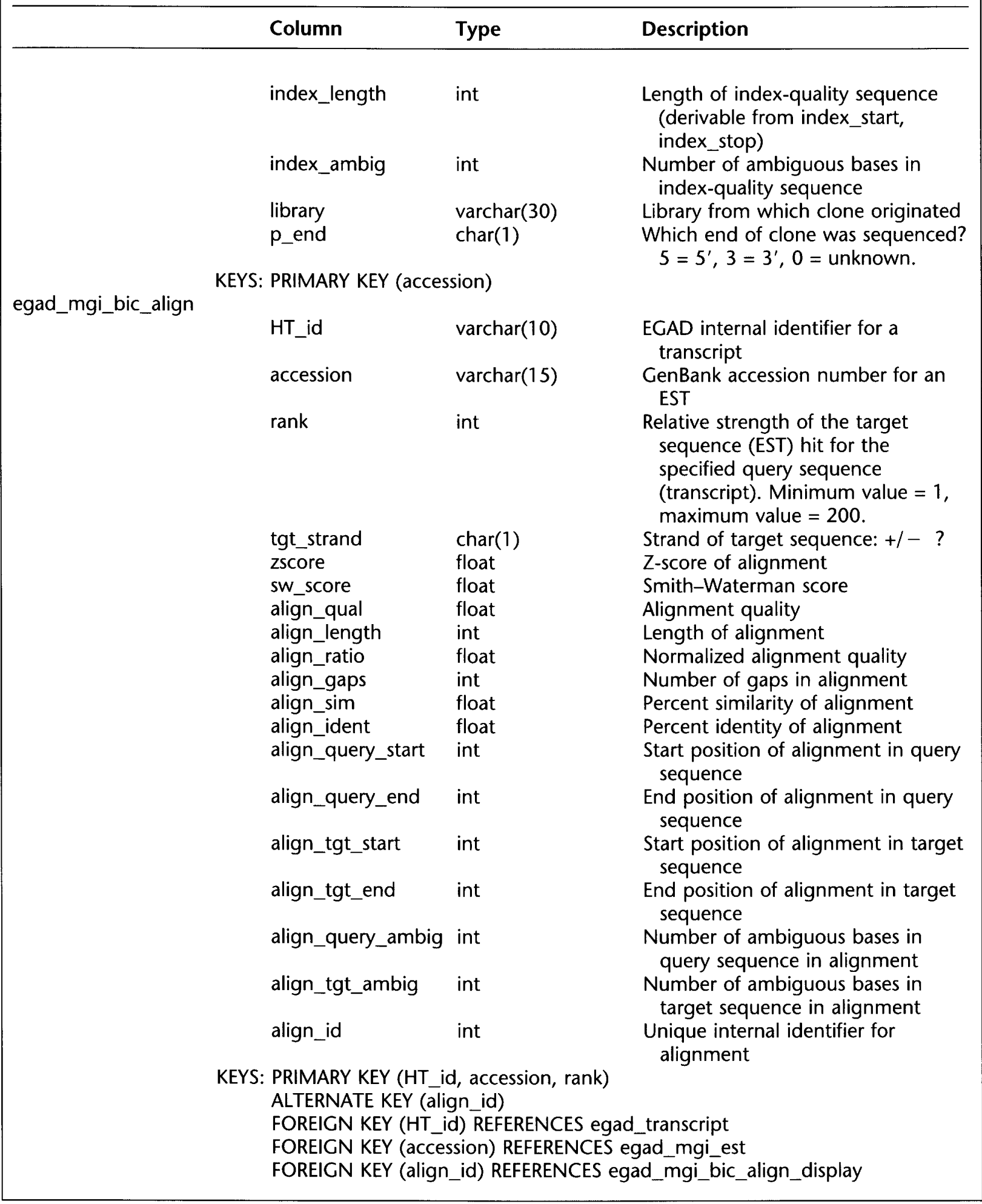


no significant vector contamination was found, the vector type was set to 0 .

\section{General Definitions and Techniques}

\section{Identifiers}

ESTs were identified uniquely by their GenBank accession number. Their clones were identified by wu clone id, the clone id assigned by the GSC. EGAD transcripts and genes were identified by their HT_id and HG_id, respectively.

\section{Definition of Match between EST and Transcript}

All queries were written as parameterized Sybase stored procedures. Every query involving alignments had input parameters @align length (length of the alignment) and @align_ident (percent identity of the alignment). A transcript $\mathbf{t}$ was considered to match or hit an EST $\mathbf{e}$ if there was a row in the egadmgi bic align table with HT_id = t, accession $=\bar{e}$, align_length $\geqslant$ @align_length and align_ident $\geqslant @$ align_ident. An EGAD gene was counted as hit by an EST if at least one transcript associated with it was hit by that EST.

\section{Identification of ESTs as 3' or 5' Sequence Reads}

The EGAD transcript sequence is reported $5^{\prime}$ to $3^{\prime}$; by definition, the + strand of the transcript is its coding strand. Therefore, a + strand hit by an EST on the EGAD transcript identifies the coding strand of the EST, and a - strand hit corresponds to the noncoding strand. Due to the antiparallel nature of DNA, and the fact that sequencing reactions proceed $5^{\prime}$ to $3^{\prime}$, a $5^{\prime}$ read from a cDNA clone represents the + strand of the gene, and a 3 ' read represents the - strand. Regardless of their label in the data base, 3' ESTs are in the same orientation as the - strand of a transcript, and $5^{\prime}$ ESTs are in the same orientation as the + strand.

\section{Summary of Results by Library}

Summaries and subtotals grouped by library were accomplished using the SQL GROUP BY operator, combined with aggregate functions such as sum, max, min, avg, and count.

\section{Detailed Descriptions of Selected Queries}

The relational data-base schema was designed specifically to facilitate the queries over sequence alignments comprising this study. Consequently, many queries consisted of relatively simple SQL statements using the general definitions and techniques outlined. Detailed descriptions of the more complex queries are provided below.

\section{Reversed Clones/Mislabeled Ends}

A $3^{\prime}$ EST is one that hits the - strand of an EGAD tran- script, and a 5' EST is one that hits the + strand of an EGAD transcript. This independent identification of $3^{\prime}$ and $5^{\prime}$ reads was compared with an ESTs wu_read id, the identifier given to the sequence read by the GSC. A true $3^{\prime}$ read should correspond to a wu_read id containing .s, and a true $5^{\prime}$ read should correspond to a wu read id containing .r. Where discrepancies arise, either the sequence reads have been mislabeled or the clone's orientation was reversed during library construction. Since putative reversed clones were eliminated from the EGAD data set by identifying pairs of transcripts that strongly hit the same EST on different strands, each EST hits EGAD either on the + or the - strand.

The query strategy is as follows. Identify ESTs whose wu_read id corresponds to the strand on which the EST hits, and ESTs whose wuread id disagrees with the strand on which the EST hits. For each clone, use the SQL GROUP BY operator and count function to compute numaccurate (the number of ESTs with accurate wu_readids) and numests (the total number of ESTs associated with the clone). A clone's orientation completely agrees with EGAD if numaccurate $=$ numests. $\mathrm{A}$ clone's orientation completely disagrees with EGAD if numaccurate $=0$. A clone is in mixed agreement with EGAD if numaccurate < numests and numaccurate $\neq 0$.

\section{Lane Tracking/Chimeric Clones}

Using the egad mgi_bic_align, egad_transcript, and egad mgi_est tables and the definition of $3^{\prime}$ and 5' EST, two sets of gene-clone pairs were identified: gene-clone pairs where the gene hits the clone via a true $3^{\prime}$ EST from that clone, and pairs where the gene hits the clone via a true 5' EST from that clone. From these pairs, clones were identified that are in both subsets, i.e., they have at least one EGAD hit on each of their ends. Of these, a lane tracking error/chimeric clone was identified as a clone for which the set of genes hit by its 3' EST(s) and the set hit by its 5' EST(s) are disjoint-the 3' and 5' EST hits have no genes in common.

\section{Verifying Estimated Insert Sizes}

The query strategy was as follows. Identify ESTs that hit only one EGAD transcript. Of these, retrieve clones with both $3^{\prime}$ and 5' ESTs hitting the same transcript. Of these, require that a clone's $5^{\prime}$ and $3^{\prime}$ ESTs hit in the expected manner, i.e., the $5^{\prime}$ hit begins upstream of the $3^{\prime}$ hit, and the $3^{\prime}$ hit ends downstream of the $5^{\prime}$ hit: (align queryend of $3^{\prime}$ EST alignment $\geqslant$ align_query_end of $5^{\prime}$ EST alignment) and (align query start of 5' EST alignment $\leqslant$ align_query_start of $3^{\prime}$ EST alignment). Calculate the putative insert size of the clone from the alignment: insert size $=$ (align_query_end of $3^{\prime}$ EST alignment-align_query_start of 5 ' EST alignment). This calculated size $\mathbf{p}$ was compared with the reported insert size $\mathbf{i}$, and the difference $\mathbf{d}$ expressed as a percentage of the calculated size: $\mathbf{d}=100^{*} \mathbf{p}-\mathbf{i} / \mathbf{p}$.

\section{Internal Priming/Alternative 3 ' Ends}

This query required two input parameters in addition to 


\section{AARONSON ET AL.}

the two parameters specifying the match criterion. @close_enough was the maximum permitted distance of the alignment from the $3^{\prime}$ end of the transcript in order for the alignment to be considered at the $3^{\prime}$ end of the transcript. @close enough arich was the maximum permitted distance of the alignment from the $5^{\prime}$ end of an A-rich region on the transcript in order for an internal priming event to be inferred.

For this query, only 3 ' hits (hits on the - strand of the transcript) were considered. A hit was considered to be internal if the alignment was more than @close enough bp from the end of the transcript: (capto polya - align_query_end) $>$ @close_enough. The query strategy was as follows. Identify $3^{\prime}$ ESTs hitting only internal sites on transcripts. Of these, identify the ESTs with poly(A) signals within 35 bp of their $3^{\prime}$ ends by looking up the EST in the egad_mgi_est polya table. These EST hits are interpreted as representing alternative $3^{\prime}$ ends of the EGAD gene. Of the ESTs hitting internal sites but without poly(A) signals, identify those that hit some transcript within@close_enough_arich and upstream of an A-rich site on the transcript: (egad a rich.startpos - align_query_end) $\leqslant @$ close_enough arich and (egad_a_rich.startpos-align_query. end) $\geqslant 0$. These hits are interpreted as instances of internal priming.

\section{ACKNOWLEDGMENTS}

We thank B. Waterston, R. Wilson, M. Marra, L. Hillier and the GSC team, G. Lennon, B. Soares, and the other members of IMAGE, C. Overton and M. Gibson of CBIL, M. Boguski and C. Tolstoshev of NCBI, and A. Williamson and C.T. Caskey of Merck Research Laboratories. We also thank the reviewers for their critical and insightful comments, which have strengthened the paper considerably.

The publication costs of this article were defrayed in part by payment of page charges. This article must therefore be hereby marked "advertisement" in accordance with 18 USC section 1734 solely to indicate this fact.

\section{REFERENCES}

Aaronson, J.S. and K.O. Elliston. 1996.

$\mathrm{ftp} / /$ avery.merck.com/mgi/IndexReport.

Adams, M.D., J.M. Kelley, J.D. Gocayne, M. Dubnick, M.H. Polymeropolous, H. Xiao, C.R. Merril, Wu, B. Olde, R.F. Moreno, A.R. Kerlavage, W.R. McCombie, and J.C. Venter. 1991. Complementary DNA sequencing: Expressed sequence tags and human genome project. Science 252: 1651-1656.

Adams, M.D., A.R. Kerlavage, R.D. Fleischmann, R.A. Fuldner, C.J. Bult, N.H. Lee, E.F. Kirkness, K.G. Weinstock, J.D. Gocayne, O. White, G. Sutton, J.A. Blake, R.G. Brandon, M. Chiu, R.A. Clayton, R.T. Cline, M.D. Cotton, J. Earle-Hughes, L. Fine, L.M. FitzGerald, W.M. FitzHugh, J.L. Fritchman, N.S. Geoghagen, A. Giodek, C.L. Gnehm, M.C. Hanna, E. Hedblom, P.S. Hinkle Jr., J.M. Kelley, K.M. Klimek, J.C. Kelley, L. Liu, S.M. Marmaros, J.M. Merrick, R.F. Moreno-Palanques, L.A. McDonald, D.T. Nguyen, S.M. Pelligrino, C.A.
Phillips, S.E. Ryder, J.L. Scott, D.M. Saudek, R. Shirley, K.V. Small, T.A. Spriggs, T.R. Utterback, J.F. Weldman, Y. Li, R. Barthlow, D.P. Bednarik, L. Cao, M.A. Cepeda, T.A. Coleman, E. Collins, D. Dimke, P. Feng, A. Ferrie, C. Fischer, G.A. Hastings, W. He, J. Hu, K.A. Huddleston, J.M. Greene, J. Gruber, P. Hudson, A. Kim, D.L. Kozak, C. Kunsch, H. Ji, H. Li, P.S. Meissner, H. Olson, L. Raymond, Y. Wei, J. Wing, C. Xu, G. Yu, S.M. Ruben, P.J. Dillon, M.R. Fannon, C.A. Rosen, W.A. Haseltine, C. Fields, C.M. Fraser, and J.C. Venter. 1995. Initial assessment of human gene diversity and expression patterns based upon 83 million nucleotides of cDNA sequence. Nature 377: 3-174.

Altschul, S.F., W. Gish, W. Miller, E.W. Myers, and D.J. Lipman. 1990. Basic local alignment search tool. J. Mol. Biol. 215: 403-10.

Benson, D., M. Boguski, D. Lipman, and J. Ostell. 1994. GenBank. Nucleic Acids Res. 22: 3441-3444.

Birnstiel, M.L., M. Busslinger, and K. Strub. 1985. Transcription termination and 3 ' processing: The end is in site Cell 41: 349-359.

Blevins, R., J. Aaronson, J. Myerson, G. Hamm, and K. Elliston. 1995. PROFILER: A tool for automatic searching of internally maintained data bases. Comput. Appl. BioSci. 11: $667-673$.

Boguski, M.S. and G.D. Schuler. 1995. ESTablishing a human transcript map. Nature Genet. 10: 369-371.

Boguski, M.S., T.M.J. Lowe, and C.M. Tolstoshev. 1993. dbEST -Database for "expressed sequence tags." Nature Genet. 4: 332-333.

Chen, P.P. 1976. The entity-relationship model-Towards a unified view of data. ACM Trans. Database Sys. 1: 9-36.

Compugen. 1995. BIOCCELERATOR Users Manual. http://www.compugen- us.com/.

Cooke, R., M. Raynal, M. Laudie, F. Grellet, M. Delseny, P.C. Morris, D. Guerrier, J. Giraudat, F. Quigley, G. Clabault, Y.F. Li, R. Mache, M. Krivitzky, I.J. Gy, M. Kreis, A. Lecharny, Y. Parmentier, J. Marbach, J. Fleck, B. Clement, G. Philipps, C. Herve, C. Bardet, D.

Tremousaygue, and J. Hofte. 1996. Further progress towards a catalogue of all Arabidopsis genes: Analysis of a set of 5000 non-redundant ESTs. Plant J. 9: 101-124.

Costanzo, F., L. Castagnoli, L. Dente, P. Arcari, M. Smith, P. Costanzo, G. Raugel, P. Izzo, T.C. Pietronaolo, L. Bougueleret, F. Cimino, F. Salvatore, and R. Cortese. 1983. Cloning of several cDNA segments coding for human liver proteins. EMBO J. 2: 57-61.

Efstratiadis, A., J.W. Posakony, T. Maniatis, R.M. Lawn, C. O'Connell, R.A. Spritz, J.K. DeRiol, B.G. Forget, S.M. Weissman, J.L. Slightom, A.E. Blechl, O. Smithies, F.E. Baralle, C.C. Shoulders, and N.J. Proudfoot. 1980. The 


\section{AN ASSESSMENT OF HIGH-IHROUGHPUT EST SEQUENCE DATA}

structure and evolution of the human beta-globin gene family. Cell 21: $653-658$.

Genetics Computer Group. 1994. Program manual for the Wisconsin package. Genetics Computer Group, Madison, WI.

Hillier, L., G. Lennon, M. Becker, M. Bonaldo, B. Chiapelli, S. Chissoe, N. Dietrich, T. DuBuque, A. Favello, W. Gish, M. Hawkins, M. Hultman, T. Kucaba, M. Lacy, M. Le, N. Le, E. Mardis, B. Moore, M. Morris, C. Prange, L. Rifkin, T. Rohlfing, K. Schellenberg, M. Soares, F. Tan, E. Trevaskis, K. Underwood, P. Wohldman, R. Waterston, R. Wilson, and M. Marra. 1996. Generation and analysis of 280,000 human expressed sequence tags. Genome Res. (this issue).

Houlgatte, R., R. Mairage-Samson, S. Duprat, A. Tessier, S. Bentolila, B. Lamy, and C. Auffray. 1995. The Genexpress Index: A resource for gene discovery and the genic map of the human genome. Genome Res. 5: 272-304.

Khan, A.S., A.S. Wilcox, M.H. Polymeropoulos, J.A. Hopkins, T.J. Stevens, M. Robinson, A.K. Orpana, and J.M. Sikela. 1992. Single pass sequencing and physical and genetic mapping of human brain cDNAs. Nature Genet. 2: 180-185.

Ko, M.S., X. Wang, J.H. Horton, M.D. Hagen, N. Takahashi, Y. Maezaki, and J.H. Nadeau. 1994. Genetic mapping of $40 \mathrm{cDNA}$ clones on the mouse genome by PCR. Mamm. Genome 5: 349-355.

Lennon, G.G., C. Auffray, M. Polymeropoulos, and M.B. Soares. 1996. The I.M.A.G.E. Consortium: An Integrated Molecular Analysis of Genomes and Their Expression. Genomics 33: 151-152.

Nishikawa, T. and K. Nagai. 1996. EST error analysis in a large-scale GenBank search of ESTs using rapid-identity-searching program for DNA sequences. In Genome mapping and sequencing, Cold Spring Harbor Laboratory Press, Cold Spring Harbor, NY.

Okubo, K., N. Hori, R. Matoba, T. Niiyama, A. Fukushima, Y. Kojima, and K. Matsubara. 1992. Large scale cDNA sequencing for analysis of quantitative and qualitative aspects of gene expression. Nature Genet. 2: $173-179$.

Pearson, W.R. 1991. Searching protein sequence libraries: Comparison of the sensitivity and selectivity of the Smith-Waterman and FASTA Algorithms. Genomics 11: $635-650$.

Smith, T.F. and M.S. Waterman. 1981. Identification of common molecular subsequences. J. Mol. Biol.

147: 195-197.

Soares, M.B., M. Bonaldo, P. Jelene, L. Su, L. Lawton, and A. Efstratiadis. 1994. Construction and characterization of a normalized cDNA library. Proc. Natl. Acad. Sci. 91: 9228-9232.
Sybase. 1994. Sybase SQL server reference manual (2 vols) Server Publication Group, Sybase, Inc., Emeryville, CA.

Szeto, E. and V.M. Markowitz. 1993. Erdraw 5.3: A graphical editor for extended entity-relationship schemas. Reference manual. Lawrence Berkeley National Laboratory, Berkeley, CA.

Wall, L. and R.L. Schwartz. 1992. Programming Perl. O'Reilly and Associates. Sebastopol, CA.

Waterson, R., C. Martin, M. Craxton, C. Huynh, A. Coulson, L. Hillier, R. Durbin, P. Green, R. Shownkeen, N. Halloran, M. Metzstein, T. Hawkins, R. Wilson, M. Berks, Z. Du, K. Thomas, J. Thierry-Mieg, and J. Sulston. 1992. A survey of expressed genes in Caenorhabditis elegans. Nature Genet. 1: 114-123.

WebMaster. 1996. http://www-bio.llnl.gov/bbrp/image/ humlib_info.html.

White, O. and R. Kerlavage. 1996. TDB: New databases for biological discovery. Methods Enzymol. 266: 24-40.

Wilcox, A.S., A.S. Khan, J.A. Hopkins, and J.M. Sikela. 1991. Use of 3' untranslated sequences of human cDNAs for rapid chromosome assignment and conversion to STSs: Implications for an expression map of the genome. Nucleic Acids Res. 19: 1837-1843.

Williamson, A.R., K.O. Elliston, and J.L. Sturchio. 1995. The Merck Gene Index, a public resource for genomics research. J. NIH Res. 7: 61-63.

Received June 13, 1996; accepted in revised form August 5, 1996. 


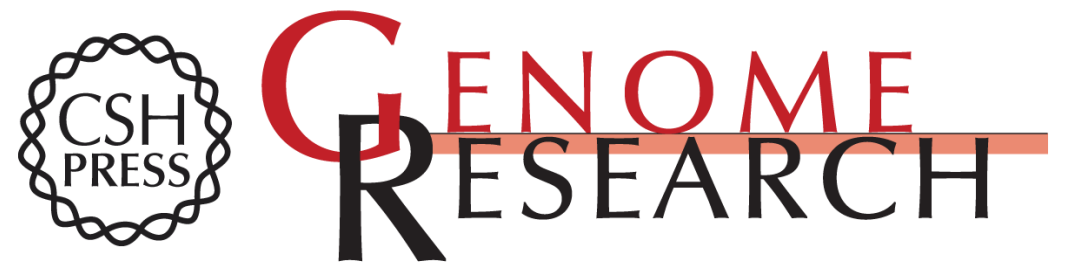

\section{Toward the development of a gene index to the human genome: an assessment of the nature of high-throughput EST sequence data.}

J S Aaronson, B Eckman, R A Blevins, et al.

Genome Res. 1996 6: 829-845

Access the most recent version at doi:10.1101/gr.6.9.829

References This article cites 24 articles, 3 of which can be accessed free at:

http://genome.cshlp.org/content/6/9/829.full.html\#ref-list-1

\section{License}

Email Alerting Receive free email alerts when new articles cite this article - sign up in the box at the Service top right corner of the article or click here.

\section{Affordable, Accurate Sequencing.}

To subscribe to Genome Research go to:

https://genome.cshlp.org/subscriptions 